\title{
Effectiveness of Structured Teaching Programme on Bio-Medical Waste Management
}

\author{
Manish Patidar ${ }^{1}$, Pavan Kumar Jain ${ }^{2}$ Ravindra H. N. ${ }^{3}$ \\ ${ }^{I}$ Student, Sumandeep Nursing College, Sumandeep Vidyapeeth, Piparia, Vadodara-391760, Gujarat, India, \\ ${ }^{2}$ Associate Professor, Department Of Medical Surgical Nursing, Sumandeep Nursing College, Sumandeep \\ Vidyapeeth, Piparia, Vadodara-391760, Gujarat, India. \\ ${ }^{3}$ Principal, Sumandeep Nursing College, Sumandeep Vidyapeeth, Piparia, Vadodara-391760, Gujarat, India,
}

\begin{abstract}
:
Background: Healthcare is one of the fastest growing sectors in India. The healthcare facilities are a basic requirement of human kind but these are also sources of life threatening wastes and toxins. The Nurses spend maximum time with patients in the ward than any other member of the health team, it increases their exposure and risk to the hazards present in hospital environment, mainly from Bio-Medical Waste. They need to be well equipped with latest information, skills and practices in managing this waste besides reducing hospital-acquired infections to protect their own health. They are also responsible for preventing risk due to waste to the other members of health team and community at large.
\end{abstract}

Aims and objectives: The study aimed at assessing the knowledge of Nurses regarding Biomedical Waste Management, evaluate the effectiveness of Structure Teaching Programme on Bio-Medical Waste Management and find out association between pre test knowledge score and selected demographic variables.

Material and Methods: A one group pre-test post-test pre-experimental design and evaluative approach was adopted. The study was conducted among 60 staff nurses conveniently selected from two hospitals of Vadodara. The content validity of the tool and teaching plan was established. The reliability of tool was established by testing the internal consistency by using Test -retest method.

Results: Result of study indicate that p-value $=0.000<0.01$, the difference between the Pre-test and Post-test scores is highly significant at $1 \%$ level of significance this shows that the Structured Teaching Programme on Bio-Medical Waste Management is effective.

Conclusion: This study concluded that structure teaching program is effective tools to improve the knowledge of staff nurses regarding bio-medical management.

Key words: Assess, Effectiveness, Structural Teaching Programme, Bio-Medical Waste, Nurses, Hospital

\section{Introduction}

Bio-Medical Waste means any waste which is generated during the diagnosis, treatment or immunization of human beings or in research activities or in the production or testing of biological and including categories mentioned in the schedule one of Bio-Medical Waste rules 2000 by Ministry of Environment and Forest notification. ${ }^{[1]}$

Healthcare is one of the fastest growing sectors in India. The healthcare facilities are a basic requirement of human kind but these are also sources of life threatening wastes and toxins. According to World Health Organization reports, $85 \%$ of hospital wastes are actually non-hazardous, whereas $10 \%$ are infectious and 5\% are non-infectious. ${ }^{[2]}$

Health-care waste management in India is receiving greater attention due to recent regulations (The Biomedical Wastes (Management \& Handling) Rules, 1998). The waste generation rate ranges between 0.5 and $2.0 \mathrm{~kg} / \mathrm{bed} / \mathrm{day}$. It is estimated that annually about 0.33 million tons of wastes are generated in India. ${ }^{[3]}$

Health-care waste can cause serious harm if not managed properly. For example, in 2007, WHO estimated that injections with contaminated syringes caused 21 million hepatitis B virus (HBV)infections (32\% of all new infections), two million hepatitis C virus (HCV) infections (40\% of all new infections) and 260000 HIV infections (5\% of all new infections). In addition, health-care activities generate significant amounts of hazardous waste such as mercury and expired pharmaceuticals, as well as large amounts of general waste. ${ }^{[4]}$

The Nurses spend maximum time with patients in the ward than any other member of the health team, it increases their exposure and risk to the hazards present in hospital environment, mainly from Bio-Medical Waste. They need to be well equipped with latest information, skills and practices in managing this waste besides reducing hospital-acquired infections to protect their own health. They are also responsible for preventing risk due to waste to the other members of health team and community at large. ${ }^{[5]}$ 
Among all health care personnel, Nurses providing more and long health services in hospitals. It has been proved that the nurses are more victims of Hepatitis B and HIV infection because not handling BioMedical Waste properly. ${ }^{[6]}$

While going through in wast and in depth review of literature regarding Bio-Medical Waste Management \& the observation of management of BMW in Indian hospitals, the researcher has interest \& motivation to educate the respective personnel specially Nurses who play a vital role in BMWM. By keeping all these points in brain, researcher has selected the topic on BMWM among Staff Nurses working in hospitals of Vadodara.

\section{Statement of the problem}

"A study to assess the effectiveness of Structured Teaching Programme on Bio-Medical Waste Management among Nurses working in selected Hospitals at Vadodara."

\section{Objectives of the study}

1. To assess the existing level of knowledge of Nurses regarding Biomedical Waste Management working in selected Hospitals at Vadodara.

2. To evaluate the effectiveness of STP on Bio-Medical Waste Management among Nurses working in selected Hospitals at Vadodara.

3. To find out association between pre test knowledge score and selected demographic variables.

\section{Hypotheses}

$\mathbf{H}_{1}$ : There will be significant difference in the knowledge score of staff nurses before and after STP regarding Bio-Medical Waste Management.

$\mathbf{H}_{2}$ : There will be significant association between pre test knowledge score with their selected demographic variables.

\section{Materials And Methods}

Research Approach: Evaluative research approach was used.

Research Design: A one group pre-test post-test Pre experimental research design was adopted

Setting of the Study: The study was conducted in two selected hospitals of Vadodara district.

Target Population: The target population for this study consisted of nurses working in hospital.

Sample: The sample for the present study comprises of 60 nurses of selected hospitals of Vadodara.

Sampling technique: Non-probability convenience sampling technique was used to select the sample for this study.

Development of tool for data collection: it consists of 2 parts:-

The researcher prepared a Self Reportive Structured Interview questionnaire is used as tool for the study. The Self Reportive Structured Interview tool consists of two sections

PART: A-Deals with the demographic data of the samples such as Age, Gender, Educational Qualification, Clinical experience \& Participation in Inservice Programme/Training/Seminar regarding Bio Medical Waste Management.

PART: B- It Consisted of a 30 multiple choice questionnaire (MCQs) to assess the Knowledge of Nurses working in selected Hospitals at Vadodara regarding Bio-Medical Waste Management.

Validity of instrument: The Self Reportive Structured Interview tool and Structured Teaching Programme were given to 11 experts along with the blue print and objectives of the study to establish the content validity of the tool and STP regarding Bio-Medical Waste Management. The experts were from the field of Nursing and Medical, Research department. They were requested to give their opinion and suggestions regarding the relevancy of the items in the tool. 
Reliability: After obtaining formal administrative permission the Gujarat and English version of the tool was administered to 7 samples selected as per the set criteria. The scores were calculated and then given for statistical analysis. The reliability was established by using test re-test method.

Data collection procedure: Prior final study a formal permission is obtained on 25.10 .2013 from the medical superintendent of Dhiraj hospital and Chiranjeev Childern's Hospital Vadodara. Data was collected from 17.11.2013 to 20.11.2013. After identifying the samples objectives of the study were discussed and consent for the participation in the study was taken from the selected group. The investigator assured the subjects about the confidentiality of the data. The investigator herself administered the questionnaire for the pre-test.

\section{Analysis of data}

Both descriptive and inferential statistics analyzed on the basis of the objectives and hypotheses of the study. The knowledge of nurses regarding Bio-medical waste management assessed before and after the administration of STP would be calculated using mean, median, range and standard deviation.

The significance of difference between the mean pre-test and post-test knowledge score of internship nurses would be calculated using paired' $t$ ' test. The association between demographic variables and post-test knowledge score regarding prevention and control of tuberculosis would be determined by chi-square test and ANOVA. Data presented in the form of tables and graphs.

\section{Results}

The analysis is made on the basis of objectives and hypothesis. The data analysis is planned to include descriptive and inferential statistics. Data is analysis in following parts:

Part-I:-Analysis of demographic data of samples

Part-II:-Analysis regarding effectiveness of STP

Part-III:-Analysis regarding association between pre-test knowledge score and demographic variables

Part-IV:-Analysis of various aspects of BMWM

\section{Section I: - Analysis Of Demographic Data Of Samples}

$>$ Age wise distribution of sample reveals that the majority 36.7\% samples belong to the Age group of 22-26 years of age while in the Age group of 30-34 years only 6.7\% samples belong to this category.

$>$ Gender wise distribution of sample reveals that majority $78.3 \%$ of the samples were females and $21.7 \%$ of the samples were male.

$>$ Educational qualification wise distribution of sample reveals that about $61.7 \%$ of the Nurses Educational qualification is ANM Nursing while $11.7 \%$ Nurses Educational qualification is B.Sc. Nursing.

$>$ Clinical experience wise distribution of the Nurses show that about $60.0 \%$ of the Nurses Clinical experience is below 5yrs. While about $3.3 \%$ of Nurses is having 10 to 15 yrs Clinical experience.

$>$ The finding related to previously attended BMWM programme, about 46.7\% of Nurses attended BMWM programme and $53.3 \%$ of Nurses not attended any programme or seminar related to Bio-medical Waste Management.

\section{Section Ii: - Analysis Regarding Effectiveness Of Stp}

Since $\mathrm{p}$-value $=0.000<0.01$, the difference between the Pre-test and Post-test scores is highly significant at $1 \%$ level of significance this shows that the Structured Teaching Programme on Bio-Medical Waste Management is effective.

\begin{tabular}{|c|c|c|c|c|c|c|c|c|}
\hline \multicolumn{1}{|c|}{ Table:-Paired Samples Statistics } \\
\hline Test & Mean & $\mathrm{N}$ & Std. Deviation & Std. Error Mean & $\begin{array}{c}\text { Coefficient of } \\
\text { Correlation }\end{array}$ & $\mathrm{t}$ & $\mathrm{P}$ & Significance \\
\hline $\begin{array}{c}\text { Pre-test } \\
\text { Post-test }\end{array}$ & 14.28 & 60 & 4.322 & .558 & .771 & 22.569 & .000 & $\mathrm{~S}$ \\
\cline { 2 - 9 } & 22.43 & 60 & 2.825 & .365 & .771 & \\
\hline
\end{tabular}




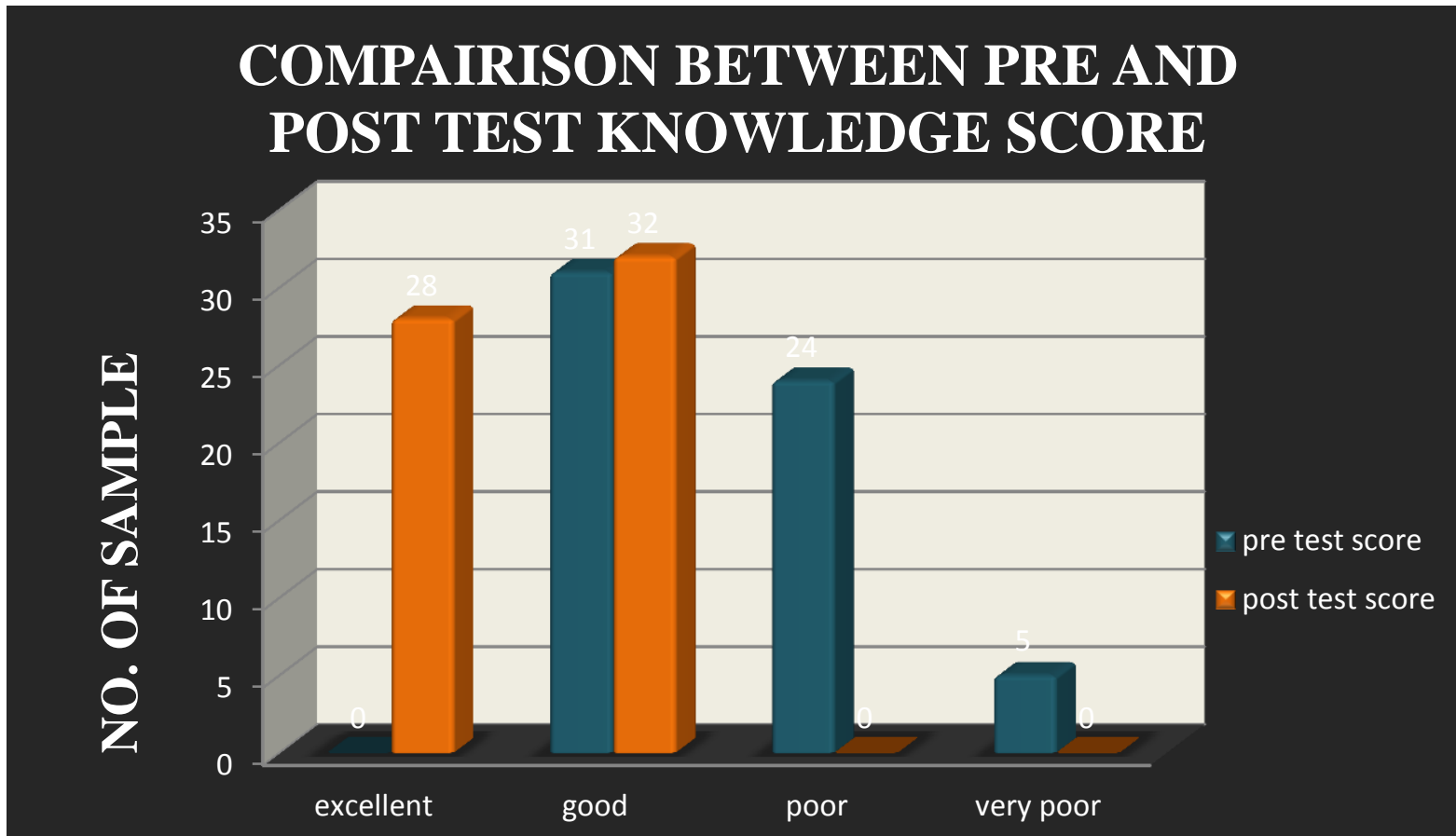

KNOWLEDGE SCORE INTERPRETATION

Fig. 1 bar diagram shows comparison between pre test and post test knowledge score of Structured Teaching Programme regarding Bio-Medical Waste Management

Section Iii: Analysis Regarding Association Between Pre-Test Knowledge Score And Demographic Variables

\begin{tabular}{|c|c|c|c|c|c|c|c|}
\hline \multicolumn{8}{|c|}{ Table:9 -Association Between Pre-Test Score Of Structured Teaching Program And Selected Demographic Variable } \\
\hline \multicolumn{8}{|c|}{ Association Between Pre-Test Score Of Structured Teaching Program And Age Of Sample } \\
\hline Age In Years & Mean & $\mathrm{N}$ & Std. Deviation & $\mathrm{F}$ & $\mathrm{P}$ & \multicolumn{2}{|c|}{ Significance Level } \\
\hline Below - 22 & 14.15 & 13 & 3.211 & \multirow{6}{*}{.597} & \multirow{6}{*}{.666} & \multirow{6}{*}{\multicolumn{2}{|c|}{ Ns }} \\
\hline $22-26$ & 14.77 & 22 & 5.004 & & & & \\
\hline $26-30$ & 12.55 & 11 & \multirow{2}{*}{$\begin{array}{l}4.034 \\
4.830\end{array}$} & & & & \\
\hline $30-34$ & 15.00 & 4 & & & & & \\
\hline $34-$ Above & 15.00 & 10 & 4.397 & & & & \\
\hline Total & 14.28 & 60 & 4.322 & & & & \\
\hline \multicolumn{8}{|c|}{ Association Between Pre-Test Score Of Structured Teaching Program And Gender Of Sample } \\
\hline Gender & Mean & $\mathrm{N}$ & Std. Deviation & $\mathrm{F}$ & $\mathrm{P}$ & \multicolumn{2}{|c|}{ Significance Level } \\
\hline Male & 14.85 & 13 & 3.934 & \multirow{3}{*}{.278} & \multirow{3}{*}{600} & \multirow{3}{*}{\multicolumn{2}{|c|}{ Ns }} \\
\hline Female & 14.13 & 47 & 4.451 & & & & \\
\hline Total & 14.28 & 60 & 4.322 & & & & \\
\hline \multicolumn{8}{|c|}{ Association Between Pre-Test Score Of Structured Teaching Program And Educational Qualification Of Sample } \\
\hline \multicolumn{2}{|c|}{ Educational Qualification } & Mean & $\mathrm{N}$ & eviation & $\mathrm{F}$ & $\mathrm{P}$ & Significance Level \\
\hline \multicolumn{2}{|c|}{ Anm } & 13.05 & \multicolumn{2}{|c|}{3.922} & \multirow{7}{*}{7.846} & \multirow{7}{*}{.001} & \multirow{7}{*}{ S } \\
\hline & & 14.94 & 16 & 509 & & & \\
\hline Bss & & 19.29 & 7 & 51 & & & \\
\hline $\mathrm{Pbb}$ & & 0 & 0 & 0 & & & \\
\hline $\mathrm{Ms}$ & & 0 & 0 & 0 & & & \\
\hline & & 0 & 0 & 0 & & & \\
\hline & & 14.28 & 60 & 322 & & & \\
\hline \multicolumn{8}{|c|}{ Association Between Pre-Test Score Of Structured Teaching Program And Clinical Experience Of Sample } \\
\hline \multicolumn{2}{|c|}{ Clinical Experience In Yrs } & Mean & $\mathrm{N}$ & eviation & $\mathrm{F}$ & $\mathrm{P}$ & Significance Level \\
\hline \multicolumn{2}{|c|}{ Below -5} & 14.72 & \multicolumn{2}{|c|}{4.314} & \multirow{5}{*}{1.358} & & \\
\hline & & 12.53 & 15 & 62 & & & \\
\hline & & 13.50 & 2 & 50 & & .265 & Ns \\
\hline & & 16.00 & 7 & 690 & & & \\
\hline & & 14.28 & 60 & 322 & & & \\
\hline
\end{tabular}

Analysis of variance (ANOVA) has been used to compare pre test score with selected demographic variables. As evident from the table pre test score of Structured Teaching Programme regarding Bio-Medical 
Waste Management are independent from Age group of samples. Furthermore table also reveals that there is no significant association of pre test score with Age.

As evident from the table pre test score of Structured Teaching Programme regarding Bio-Medical Waste Management are independent from Gender of samples. Furthermore tables also reveal that there is no significant association of pre test score with Gender.

As evident from the table pre-test score of Structured Teaching Programme regarding Bio-Medical Waste Management are dependent on Educational qualification of samples. Furthermore tables also reveal that there is significant association of pre test score with Educational qualification of samples.

As evident from the table pre-test score of Structured Teaching Programme regarding Bio-Medical Waste Management are independent from Clinical experience of samples. Furthermore tables also reveal that there is no significant association of pre test score with Clinical experience of samples.

As evident from the table pre-test score of Structured Teaching Programme regarding Bio-Medical Waste Management are dependent on previous participation in programme related to Bio-Medical Waste Management of samples. Furthermore tables also reveal that there is highly significant association of pre test score with previous participation in programme related to Bio-Medical Waste Management of samples.

\section{Section Iv: Analysis Of Various Aspects Of Bmwm}

$>$ Analysis of various aspects of bio-medical waste management on the basis of difference between pre test and post test knowledge score, it shows ' $t$ ' and ' $p$ ' value of pre and post test knowledge score for awareness and general concept about Bio-Medical Waste Management.

$>$ Analysis of categories of Bio-Medical Waste has highly significant difference between pre test and post test knowledge score for categories of Bio-Medical Waste.

$>$ Analysis of aspects regarding personal protective equipment for protection against Bio-Medical Hazards were highly significant difference between pre test and post test knowledge score for personal protective equipment for protection against Bio-Medical Hazards.

$>$ Analysis of aspects regarding duties and responsibilities of nurse in Bio-Medical Waste Management not have significant difference between pre test and post test knowledge score for duties and responsibilities of nurse in Bio-Medical Waste Management.

\section{Conclusion}

The findings of this study have been discussed with reference to the objectives and hypothesis. The pre testing of nurse's knowledge regarding Bio Medical Waste management show that nurses have less knowledge about Bio Medical waste management. This indicates the need for imparting necessary education and information regarding Bio Medical Waste Management.

\section{Acknowledgement}

I express my gratitude and thanks towards all who have directly or indirectly helped me to complete this study and their support in each major step of the study.

\section{Limitations of the Study}

The following points were beyond the control of the investigator.

1. The study is limited to small sample size

2. The assessment of effect of the STP is limited to one post-test conducted on the 10th day.

\section{Recommendations}

Based on the findings of the present study recommendations offered for the future study are:

- A similar study can be done on a larger sample

- A study can be done among other hospital employees.

- A study may be conducted to evaluate the effectiveness of STP versus other methods of health teaching on the similar problems.

- A comparative study can be done in urban and rural community and different large hospitals, Private hospitals and Govt. hospitals.

- A similar study can be done in more depth.

- A study can be done on association between various demographic variables, which were significant on larger samples.

- A similar study can be replicated in different setting to strengthen the findings.

- A study can be done on knowledge of practice related to Bio -Medical Waste Management among paramedical staffs. 


\section{Ethical Standards}

This study was conducted after getting approval from the Institutional Ethics Committee and after obtaining written consents from all subjects.

Source of funding: The authors did not receive any financial support from any third party related to the submitted work.

Conflict of interest: The authors had no relationship/condition/circumstances that present a potential conflict of interest.

\section{References}

[1]. www.cpcb.nic.in, Ministry of Environment and Forests, notification N.S.O. 630 (E).Biomedical waste (management and handling) rules 1998

[2]. Anand R.C. and Sidharth Satpathy, Hospital Waste Management: A holistic approach, New Delhi : Jay pee Brothers Medical Publishers (P) LTD., 2003. P.No.118

[3]. Madhuri Sharma, Hospital waste management and its monitoring, $1^{\text {st }}$ edition, jaypee publication, P.No.2-5

[4]. WHO core principles for achieving safe and sustainable management of health-care waste, WHO in Geneva on June 20 - 22 , 2007.

[5]. AFACFO, (2002) Manual Bio Medical Waste Management of hospital infection control for armed forces. Second edition Pg. No. 21.

[6]. Pandit, N.A., S.A. Tabish and G.J. Qadri, 2007. Biomedical Waste Management in a Large Teaching Hospital. JK- Practitioner, P.No. 57-59. 